account the shifting distribution of patients between different therapy options-assures that an appropriate cost-outcomes assessment is performed.

While this is more demanding in terms of both data and technical expertise than the traditional, partial approach, it is more appropriate. Unless account is taken of the range of comparator products, anticipated patterns of drug substitution for the treating population, and their impact on the structure of costs and outcomes, any assessment of the impact of introducing a new drug remains incomplete.

\section{- References}

1. Australia, Department of Health, Guidelines for the Pharmaceutical Industry on Preparation of Submissions to the Pharmaceutical Benefits Advisory Committee. Canberra, A.ustralia: AGPS; 1992 (revised November 1995); see Langley P. The November 1995 Revised Australian Guidelines for the Economic Evaluation of Pharmaceuticals. PharmacoEconomics 1996; 9(4):341-52, for a critique.

2. Canada, Canadian Coordinating Office for Health Technology Assessment, Guidelines for Economic Evaluation of Pharmaceuticals. Ottawa, Canada: CCOHTA; 1994.

3. New Zealand, Pharmaceutical Management Agency (PHARMAC). Operating policies and pro- cedures of Pharmaceutical Management Agency Ltd. Wellington, New Zealand: PHARMAC; 1993. 4. United Kingdom, Department of Health. Guidance on good practice in conduct of economic evaluations of medicines. PharmacoResources. 1994 (May).

5. Drummond M, Stoddart G, Torrance G. Methods for the economic evaluation of health care programmes. London: Oxford University Press; 1987.

6. For a description of the PhRMA principles see Clemens K, Townsend R, Luscombe F, Mauskopf Osterhaus J, Bobula J. Methodological and conduct principles for pharmacoeconomic research. PharmacoEconomics 1995; 8(2):169-74, and Di- vision of Drug Marketing, Advertising and Communications, Food and Drug Administration. Principles for the review of pharmacoeconomic promotion. Washington DC: 1995.

7. Langley P. Outcomes research and modeling therapeutic interventions for economic evaluations. Clin Ther 1994; 16: 538-52.

8. Langley $P$. Therapy evaluation, patient distribution and cost-outcomes ratios. Clin Ther 1995; 17: $341-7$

9. Langley P. Cost effectiveness and the allocation of therapies in a treating population. PharmacoEconomics 1996; 10: 93-8.

\title{
A Authors
}

PAUL C. LANGLEY, PH.D., is Associate Professor, Center for Pharmaceutical Economics, College of Pharmacy, University of Arizona, Tucson; SEAN D. SULLIVAN, PE.D., is Assistant Professor, Department of Pharmacy \& Health Services, University of Washington, Seatte.

CORReSPondence: Paul C. Langley, Center for Pharmaceutical Economics, College of Pharmacy, University of Arizona, fucson, A.Z 85721.

ACKNOWLEDGMENTS: To the following for constructive comments on early drafts of this paper: K. Clemans (Roche Pharmaceuticals), J. Osterhaus and R. Townsend (Glaxo-Welicome) and C. Turnbuli (Schering Plough Phamaceuticals).

Copyright (1) 1996, Academy of Managed Care Pharmacy, Inc. All rights reserved.

\section{Editor's Note}

The year 2020 marks the 25th anniversary of the Journal of Managed Care E Specialty Pharmacy. To commemorate this milestone, we are publishing a series of articles that document the changes to the journal and profession over the past 2 and a half decades. Each month we reprint an original article from a previous year, dating back to 1995. The reprinted articles feature topics of significance in our industry. Each reprinted article is accompanied by a contemporary reflection that will consider the historical significance of the topic, as well as the current and future state.

Laura E. Happe, PharmD, MPH Editor-in-Chief 